\title{
Usulan Evaluasi Sistem Keamanan Informasi Berdasarkan Standar ISO/IEC 27002:2013 pada Pondok Pesantren Kafila International Islamic School Jakarta
}

\author{
Aditya Teguh Septoaji ${ }^{1}$, Fitroh $^{2}$, Elsy Rahajeng ${ }^{3}$
}

\begin{abstract}
Abstrak - Kafila International Islamic School (KIIS) adalah sebuah pesantren (boarding school) yang mempunyai banyak prestasi di beberapa perlombaan dan nilai Ujian Nasional. Sejak 2007, KIIS sudah menerapkan standar ISO 9001:2008 sebagai standar mutu pendidikan. Namun, dengan penerapan ISO 9001:2008 belum menutup semua celah baik kelemahan (vulnerable) atau ancaman (threat) yang timbul ketika proses pembelajaran sekolah berlangsung. Dalam wawancara penulis, KIIS memerlukan solusi untuk improvisasi keamanan dan dokumentasi yang lebih baik terutama dalam fasilitas informasi, yaiu dengan melakukan penelitian evaluasi menggunakan ISO 27002:2013, penelitian Keamanan Sistem Informasi ini dilakukan pada 8 klausul, pada kebijakan keamanan informasi, keamanan informasi organisasi, keamanan sumber daya (pekerjaan), manajemen aset, kontrol akses, keamanan fisik dan lingkungan, keamanan operasi, akusisi sistem informasi, pembangunan dan pemeliharaan). Dalam penelitian ini, penulis menggunakan metode pengukuran kapabilitas tingkat kedewasaan (CMM). Dapat dihasilkan nilai kedewasaan 4 (managed) pada klausul kebijakan keamanan informasi, keamanan informasi organisasi, keamanan sumber daya dan manajemen aset. Selanjutnya Nilai kedewasaan 3 (defined) pada klausul Kontrol Akses, Keamanan fisik dan lingkungan, Keamanan operasi, Akusisi sistem informasi dan pembangunan dan pemeliharaan.
\end{abstract}

Kata Kunci- Sekolah, Keamanan Sistem Informasi, ISO 272002

\section{Pendahuluan}

$\mathrm{P}$ enggunaan teknologi informasi di berbagai organisasi saat ini sangat dibutuhkan untuk mempermudah melakukan pendataan dan pengambilan keputusan yang strategis[1]. Perkembangan teknologi informasi pada saat ini menyebabkan perubahan peran teknologi informasi bagi

Received: 16 Juli 2018; Revised: 20 Agustus 2018; Accepted: 1 September 2018.

A. T. Septoaji, staf IT di Kafila Internasional Islamic School (adityat626@gmail.com)

Fitroh, dosen Prodi Sistem Informasi UIN Syarif Hidayatullah Jakarta (fitroh@uinjkt.ac.id)

E. Rahajeng, dosen Prodi Sistem Informasi UIN Syarif Hidayatullah Jakarta (elsy.rahajeng@uinjkt.ac.id) organisasi, teknologi informasi tidak hanya difungsikan sebagai pendukung (support) tetapi menjadi bagian dari organisasi dalam mecapai kesuksesan [2]. Organisasi-pun pada hampir semua sektor membutuhkan teknologi, terutama teknologi informasi untuk setiap sistem informasi mereka. Bahkan bisa dikatakan, "teknologi informasi acapkali tidak dapat dipisahkan dengan keperluan bisnis" [3].

Perkembangan Teknologi Informasi saat ini tidak hanya berfungsi sebagai penyedia jasa layanan saja[4], melainkan diharapkan dapat berperan menjadi partner dalam menentukan strategi bisnis baru. Maka perlu memperhatikan bagaimana tata kelola teknologi informasi supaya proses berjalannya teknologi informasi dapat berjalan secara optimal dalam mendukung strategi bisnis [5].

Informasi adalah aset dalam bisnis. Karena sifatnya yang penting, maka perlu di proteksi [6]. Informasi dapat disimpan dalam berbagai macam media, seperti: media digital dan media cetak. Informasi dapat dikirim menggunakan kurir, elektronik hingga komunikasi verbal. Apapun cara penyimpanannya dan cara penyebarannya, tetap diperlukan keamanan untuk menjamin terjaganya informasi [6]. Menurut laporan Symantec (2015), tercatat 312 pelanggaran keamanan informasi dan mengakibatkan kerugian senilai 348 juta dikarenakan terbongkarnya informasi pribadi, seperti data kartu kredit, data riwayat medis, data pribadi, ID login, dan lainnya[7]. Aspek Keamanan Informasi sangat penting, terutama dalam aspek pelayanan fasilitas pendidikan, karena secara tidak langsung mempengaruhi "income" dan "outcome" dalam bisnis prosesnya [8].

Peneliti mengadakan wawancara dengan beberapa stakeholder [9] IT KIIS, wawancara pertama kepada Direktur Pendidikan KIIS, Bapak Achmad Alwasim. Beliau bahwa KIIS berencana pada Juli 2019, Kafila akan memperbaharui ISO 9001. Dari ISO 9001:2008 ke ISO 9001:2015. Hasil dari penelitian ini diharapkan dapan menambah nilai mutu untuk administrasi Pendidikan yang lebih baik untuk KIIS. Kemudian ke divisi IT bidang Alquran, menurut Bapak Abdurrohim, Admin Bidang Alquran KIIS dan sekaligus penanggungjawab aplikasi TahfizApp, perlu pedoman alur dan struktur data yang tepat dalam perancangan dan pembuatan aplikasi [10], karena 
pada ujian tahfidz semester 1 tahun 2019 misalnya, ada beberapa ujian yang gagal dikarenakan kesalahan tipe data (NaN) dalam pemrosesan input.

Wawancara dilanjutkan dengan Bapak Rifki Baisa, staf labkom spesialis jaringan. Beliau menghimbau perlu adanya pengaturan kebijakan penataan teknologi dan pencatatan aset-aset jaringan dan CCTV (control room), sering terjadi kehilangan dan kerusakan aset dan tidak terdokumentasikan dengan baik [11].

Berikutnya adalah wawancara kepada Bapak Taufiqurrohman. Sebagai kepala Laboratorium Komputer KIIS Kepala Laboratorium Komputer (labkom) mempunyai tanggung jawab untuk pemeliharaan data dan pengembangan sistem aplikasi digital yang kini sudah berjalan di KIIS. Namun, faktor dokumentasi untuk regenerasi penerus pengurus perlu dipertimbangkan. Mengingat proses regenerasi adalah proses transfer knowledge. Beliau menambahkan, ISO 9001 (yang sudah dilengkapi ISO 31000) mengenai manajemen mutu sudah dirasa cukup untuk pengendalian mutu laboratorium, namun masih ada kekurangan dalam dokumentasi Aset IT. Pada 20 Januari 2020, terjadi kehilangan data pada server sekolah (salah satu hardisk RAID server mati) dikarenakan tidak berjalannya fungsi pengecekan pada aset-aset di KIIS.

Semua masalah yang telah terjadi bukan hanya karena upaya tindakan yang kurang baik, tetapi karena belum adanya standar dari prosedur keamanan yang ada, standar operasional prosedur yang belum memenuhi standar keamanan, bahkan ada beberapa standar operasional prosedur yang mengambil dari sumber internet dan belum mengadaptasi dengan lingkungan keamanan informasi. Dari hasil wawancara tersebut, diperlukan evaluasi pada perangkat (aset) IT pada KIIS.

\section{KAJIAN PENELITIAN}

\section{A. Sistem}

Sistem merupakan kumpulan elemen/fungsi yang saling terhubung satu sama lain yang membentuk kesatuan dalam mencapai tujuan yang sama [12].

\section{B. Informasi}

Ref. [12] menguraikan, bahwa informasi adalah data yang telah diklasifikasi (disekat) kemudian dipakai sebagai bahan dalam pengambilan keputusan (decision).

\section{Sistem Informasi}

Sistem Informasi adalah suatu sistem di dalam organisasi/perusahaan yang mendukung fungsi operasi organisasi (harian, pekanan hingga rekayasa manajemen lainnya) yang bersifat manajerial untuk dapat menyediakan informasi yang berguna kepada pihak luar tertentu dengan laporan-laporan [12].

\section{Keamanan Informasi}

Dalam keamanan informasi, ancaman (threat) adalah setiap kegiatan yang dapat membahayakan informasi. Ancaman ini kerapkali akan menjadi negatif jika menguak (leaking) dan memanipulasi kerahasiaan (confidentiality), integritas (integrity), dan ketersediaan (availability) dari sebuah sistem [13].

http://journal.uinjkt.ac.id/index.php/aism

\section{E. Sistem Manajemen Keamanan Informasi}

Keberadaan dokumen "Kebijakan Keamanan" atau "Security Policies" merupakan sebuah infrastruktur keamanan yang harus dimiliki oleh sebuah organisasi atau perusahaan yang ingin melindungi aset informasi terpentingnya. Dokumen ini berisikan tata cara mengamankan informasi, baik secara langsung maupun tidak langsung [14].

\section{Metode Penelitian}

\section{A. Metode Pengumpulan Data}

\section{1) Kuesioner}

Pengumpulan data dilakukan dengan menggunakan kuesioner [15]. Narasumber yang penulis pilih adalah Kepala HRD, Kepala Labkom dan Kepala Logistik KIIS. Penulis menggunakan metode kuesioner personal (ahli) dan diisi langsung oleh responden sesuai dengan keadaan sebenar-benarnya.

\section{2) Wawancara}

Wawancara penulis lakukan dengan Direktur Pendidikan Kafila International Islamic School yang merupakan pemimpin organisasi KIIS.

\section{B. Metode Analisis Data}

1) Plan, pada tahap ini, peneliti menemui Direktur Pendidikan Kafila International Islamic School, mempelajari kembali profil, visi dan misi hingga struktur transformasi terbaru Kafila International Islamic School.

2) Do, peneliti mengamati secara langsung bagaimana manajemen berjalan pada Kafila International Islamic School. Proses yang dilakukan adalah mengidentifikasi risiko, langkah dalam indentifikasi risiko adalah sebagai berikut: Identifikasi aset pada Kafila International Islamic School. Parameter identifikasi adalah kerahasiaan informasi, keutuhan informasi dan ketersediaan informasi (CIA triad).

a) Identifikasi pada proses bisnis yang berjalan dan akan berjalan pada aspek ancaman dan kelemahan.

b) Menganalisa dan evaluasi risiko, merupakan tindak lanjut dari identifikasi risiko. Penulis menganalisa risiko, apakah risiko dapat diabaikan ataukah harus dilakukan tindakan preventif untuk menghindari risiko tersebut. Langkah yang penulis lakukan adalah:

(1) Menganalisa dampak bisnis. Penulis menggunakan metode Bussiness Impact Analysis (BIA) dalam penentuan skala.

(2) Membuat matriks level risiko untuk menganalisa risiko yang terjadi dan akan terjadi sehingga nilai dari matriks ini menjadi perhatian dalam menentukan rencana kedepannya.

(3) Jika sudah ditentutan matriksnya, diberikan prioritas pengelolaan risiko dari prioritas tinggi (darurat) hingga prioritas rendah

3) Check, proses pengecekan ini adalah pemilihan obyek kontrol dan kontrol keamanan informasi berdasarkan kondisi dan nilai risiko yang didapat dari langkah sebelumnya (matriks 
level risiko). Penulis juga mengukur kematangan keamanan sistem. Langkah penilaian kematangan sistem sebagai berikut: Kuesioner, diberikan kepada 3 bagian penting organisasi:

a) Manajemen Representatif, Kepala Labkom, Koordinator Jaringan dan Staf Labkom dengan jumlah responden sebanyak 4 orang.

b) Penilaian tingkat kematangan system, menggunakan Security Engineering Capability Maturity Level (SSE-CMM). Penjelasan penilain adalah seperti pada Tabel 1.

Tabel 1.

Tingkat Kemampuan SSE-CMM

\begin{tabular}{cl}
\hline \hline Rentang Nilai & \multicolumn{1}{c}{ Tingkat Kematangan } \\
\hline $0-0,50$ & 0 -Non Existent \\
$0,51-1,50$ & $1-$ Initial \\
$1,51-2,50$ & 2 -Repeteable \\
$2,51-3,50$ & 3 -Defined \\
$3,51-4,50$ & 4 -Managed \\
$4,51-5,00$ & 5 -Optimized \\
\hline \hline
\end{tabular}

Penghitungan yang dipakai adalah nilai hasil level kematangan rata-rata dari setiap kontrol obyek dan rata-rata keseluruhan klausul.

1. Act, penulis memberikan rekomendasi dari hasil temuan penghitungan nilai kematangan yang sudah dihitung sebelumnya sebagai bahan evaluasi proses bisnis Kafila International Islamic School.

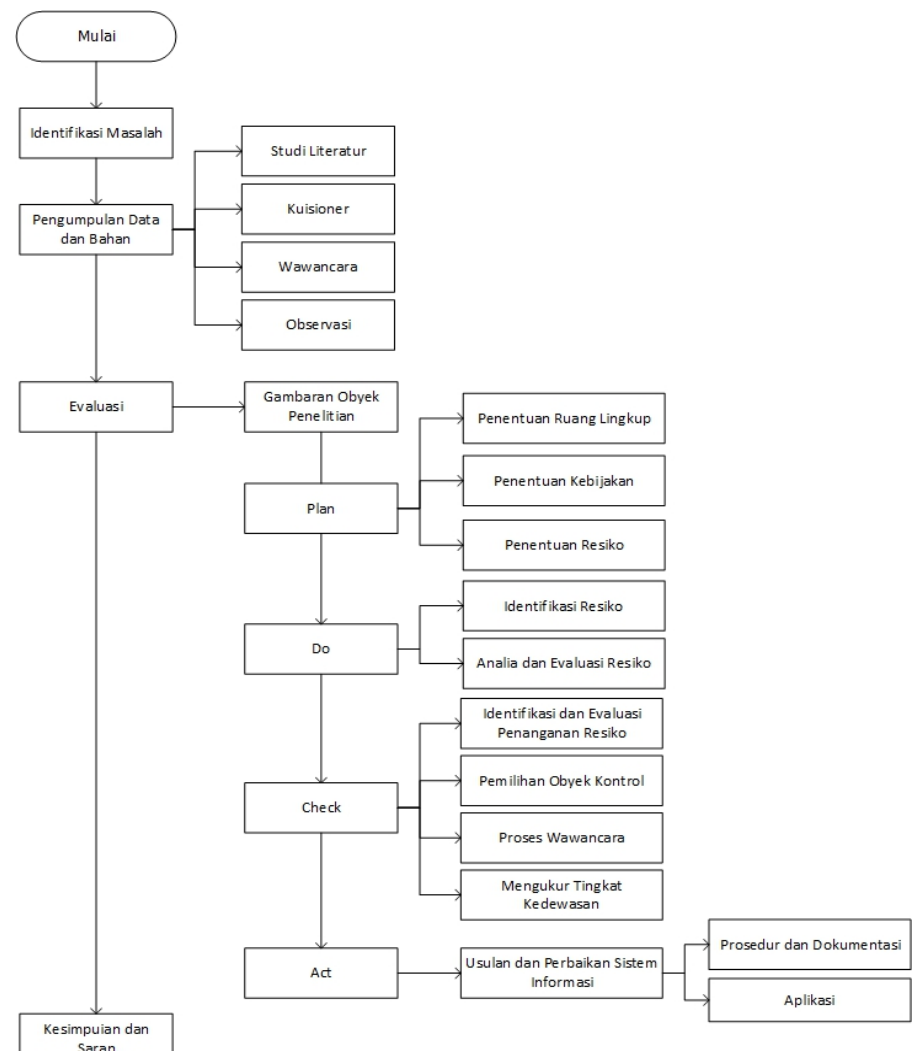

IV. HASIL

A. Plan

1) Identifikasi Aset

Tabel 2. Identifikasi Aset

\begin{tabular}{ll}
\hline \hline & Infrastruktur IT di KIIS \\
\hline Location & Jalan Raya Bogor KM 22,5 Ciracas \\
& Jakarta Timur \\
Business Application & Myschool (akademik), Ehsan \\
& (feedback), TahfizApp (alquran) \\
& Server: Redhat \\
Operating System Services & Desktop: Windows 7 dan Windows \\
& 10 \\
Network Services & Email \& Pop \\
Security & Firewall: default \\
Communication Infrastructure & LAN, WAN, Mikrotik \\
\hline \hline
\end{tabular}


Tabel 3. Spesifikasi Aset IT KIIS

\begin{tabular}{|c|c|}
\hline \multicolumn{2}{|c|}{ Spesifikasi Aset IT KIIS } \\
\hline & IBM System x3650 (2016) \\
\hline Server & $\begin{array}{l}\text { Operating System: Redhat RHEL } 7.4 \\
\text { (2017) }\end{array}$ \\
\hline & Firewall: firewall (default) \\
\hline $\begin{array}{l}\text { Labkom Backup Computer } \\
\text { (Server) }\end{array}$ & $\begin{array}{l}\text { Operating System: Windows } 10, \\
\left.\text { Intel i5 ( } 5^{\text {th }} \text { Generation }\right), 8 \text { GB RAM }\end{array}$ \\
\hline $\begin{array}{l}\text { Labkom Backup Computer } \\
\text { (MTS) }\end{array}$ & $\begin{array}{l}\text { Operating System: Windows } 7 \text { SP1, } \\
\text { Intel i5 ( } 5^{\text {th }} \text { Generation), } 8 \text { GB RAM }\end{array}$ \\
\hline $\begin{array}{l}\text { Labkom Backup Computer } \\
\text { (MA) }\end{array}$ & $\begin{array}{l}\text { Operating System: Windows } 8 \text {, Intel } \\
\left.\text { i5 ( } 5^{\text {th }} \text { Generation }\right), 8 \text { GB RAM }\end{array}$ \\
\hline Labkom Computer (Students) & $\begin{array}{l}\text { Operating System: Xubuntu vers } 20 \text {, } \\
\text { Intel i5 ( } 5^{\text {th }} \text { Generation), } 4-8 \text { GB } \\
\text { RAM }\end{array}$ \\
\hline Network & $\begin{array}{l}\text { OS: Mikrotik Vers } 6.34 \text { (updated } \\
\text { Maret 2016) }\end{array}$ \\
\hline Switch LAN-hub & $\begin{array}{l}\text { TP LINK TL-SG1024D (24 PORT) } \\
\text {-> Labkom, D-Link DES 1024D ( } 24 \\
\text { Port) -> Control Room }\end{array}$ \\
\hline Wifi Router & Tp-link TL-WR840N, Ubiquity N2 \\
\hline
\end{tabular}

\section{2) Penentuan Resiko}

\section{a. Metode Risk Assessment}

Metode yang penulis lakukan dalam penilaian resiko adalah metode matematis dengan penerapan logika.

b. Kriteria Penerimaan Resiko

Tabel 4. Kriteria Penerimaan Resiko

\begin{tabular}{|c|c|}
\hline Penerimaan Resiko & Keterangan \\
\hline $\begin{array}{l}\text { Resiko Diterima } \\
\text { (risk acceptable) }\end{array}$ & $\begin{array}{l}\text { Resiko dapat diterima organisasi } \\
\text { dengan segala dampaknya dan proses } \\
\text { bisnis dapat berjalan terus }\end{array}$ \\
\hline $\begin{array}{l}\text { Resiko direduksi } \\
\text { (risk reduction) }\end{array}$ & $\begin{array}{l}\text { Resiko dapat diterima organisasi, } \\
\text { namun organisasi mereduksi } \\
\text { dampaknya dengan menggunakan } \\
\text { kontrol keamanannya }\end{array}$ \\
\hline Resiko dihindari atau ditolak & $\begin{array}{l}\text { Organisasi perlu menghindari penyebab } \\
\text { penyebab timbulnya resiko dan } \\
\text { menghentikan aktifitasnya jika gejala } \\
\text { resiko muncul seperti mematikan } \\
\text { manual komputer server jika tidak } \\
\text { dapat dimatikan melalu command } \\
\text { promp/terminal komputer backup } \\
\text { server }\end{array}$ \\
\hline $\begin{array}{l}\text { Resiko dialihkan pada pihak } \\
\text { ketiga }\end{array}$ & $\begin{array}{l}\text { Organisasi menerima resiko tersebut } \\
\text { dengan mengalihkan kepada pihak } \\
\text { ketiga dengan kompensasi sesuai } \\
\text { perjanjian dengan perusahaan seperti: } \\
\text { vendor asuransi, garansi prosuk dan } \\
\text { lainnya. }\end{array}$ \\
\hline
\end{tabular}

\section{3) Tabel Aset Informasi KIIS}

Tabel 5. Aset Informasi KIIS

\begin{tabular}{|c|c|c|}
\hline Jenis Aset & Nama Aset & Penjelasan \\
\hline \multirow{7}{*}{ Dokumen } & Data Karyawan & Guru dan pegawai KIIS. \\
\hline & Data PSB & Siswa saat baru mendaftar \\
\hline & Data Sekolah & $\begin{array}{l}\text { Dokumentasi } \\
\text { pembelajaran. }\end{array}$ \\
\hline & Data Keasramaan & Dokumentasi keasramaan. \\
\hline & Data Tahfidz & Dokumentasi tahfidz. \\
\hline & $\begin{array}{l}\text { Data Laboratorium } \\
\text { Komputer }\end{array}$ & $\begin{array}{l}\text { Berbagai aplikasi di } \\
\text { kembangkan di labkom. }\end{array}$ \\
\hline & Aplikasi MySchool & $\begin{array}{l}\text { digunakan untuk mengeola } \\
\text { data sekolah }\end{array}$ \\
\hline \multirow{2}{*}{$\begin{array}{l}\text { Perangkat Lunak } \\
\text { Sistem }\end{array}$} & Aplikasi PSB & $\begin{array}{l}\text { digunakan untuk mengeola } \\
\text { data siswa baru }\end{array}$ \\
\hline & Aplikasi Ujian Quran & $\begin{array}{l}\text { digunakan untuk ujian } \\
\text { quran }\end{array}$ \\
\hline \multirow{11}{*}{ Perangkat Keras } & Aplikasi Asrama & $\begin{array}{l}\text { digunakan untuk } \\
\text { pengelolaan asrama }\end{array}$ \\
\hline & Laboratorium & $\begin{array}{l}\text { digunakan siswa dalam } \\
\text { proses KBM TIK }\end{array}$ \\
\hline & Mikrotik & $\begin{array}{l}\text { Jaringan Internet dan LAN } \\
\text { KIIS }\end{array}$ \\
\hline & Server & $\begin{array}{l}\text { alat penyimpanan aplikasi } \\
\text { dan data lokal }\end{array}$ \\
\hline & $\begin{array}{l}\text { Komputer Backup } \\
\text { Server }\end{array}$ & backup server \\
\hline & Komputer Asrama & bidang asrama \\
\hline & Komputer Tahfidz & bidang tahfidz \\
\hline & Komputer Admin & $\begin{array}{l}\text { pengelolaan data surat } \\
\text { menyurat KIIS hingga } \\
\text { pengelolaan data pegawai }\end{array}$ \\
\hline & CCTV Labkom & CCTV keamanan \\
\hline & Pemadam Kebakaran & $\begin{array}{l}\text { Fitur dalam gedung sebagai } \\
\text { detektor panas dan asap, bel } \\
\text { darurat, dan alat pemadam } \\
\text { kebakaran }\end{array}$ \\
\hline & $\begin{array}{l}\text { Pendingin Ruangan } \\
\text { (AC) }\end{array}$ & online 24 jam \\
\hline
\end{tabular}

\section{4) Perhitungan Nilai Aset}

Tabel 6. Nilai Aset

\begin{tabular}{clcccc}
\hline \hline \multirow{2}{*}{ Jenis Aset } & \multicolumn{1}{c}{ Nama Aset } & NC & NI & NV & NA \\
\hline & Data Karyawan & 4 & 3 & 2 & 9 \\
& $\begin{array}{l}\text { Data Penerimaan } \\
\text { Siswa Baru }\end{array}$ & 4 & 3 & 2 & 9 \\
& Data Sekolah & 4 & 4 & 4 & 12 \\
Dokumen & Data Keasraman & 4 & 3 & 4 & 11 \\
& Data Tahfidz & 4 & 3 & 4 & 11 \\
& $\begin{array}{l}\text { Data Laboratorium } \\
\text { Komputer }\end{array}$ & 4 & 4 & 4 & 12 \\
& Aplikasi MySchool & 4 & 4 & 4 & 12 \\
$\begin{array}{l}\text { Perangkat Lunak } \\
\text { Sistem }\end{array}$ & & & & & \\
&
\end{tabular}

http://journal.uinjkt.ac.id/index.php/aism 


\begin{tabular}{|c|c|c|c|c|c|}
\hline & Aplikasi PSB & 4 & 2 & 4 & 10 \\
\hline & $\begin{array}{l}\text { Aplikasi Ujian } \\
\text { Quran }\end{array}$ & 4 & 2 & 2 & 8 \\
\hline & Aplikasi Asrama & 4 & 3 & 4 & 11 \\
\hline & $\begin{array}{l}\text { Komputer } \\
\text { Laboratorium }\end{array}$ & 2 & 3 & 3 & 8 \\
\hline & Mikrotik & 4 & 4 & 4 & 12 \\
\hline & Server & 4 & 4 & 4 & 12 \\
\hline & $\begin{array}{l}\text { Komputer Backup } \\
\text { Server }\end{array}$ & 4 & 2 & 2 & 8 \\
\hline & Komputer Asrama & 4 & 3 & 3 & 10 \\
\hline Perangkat neras & & & & & \\
\hline & Komputer Tahfidz & 3 & 3 & 2 & 8 \\
\hline & Komputer Admin & 4 & 4 & 4 & 12 \\
\hline & CCTV Labkom & 4 & 4 & 4 & 12 \\
\hline & $\begin{array}{l}\text { Pendingin Ruangan } \\
\text { (AC) Labkom }\end{array}$ & 4 & 1 & 4 & 9 \\
\hline & $\begin{array}{l}\text { Pemadam } \\
\text { Kebakaran (fire } \\
\text { extinguisher dan } \\
\text { sensor api dalam } \\
\text { gedung) }\end{array}$ & 2 & 2 & 4 & 8 \\
\hline
\end{tabular}

\section{5) Identifikas Ancaman}

Tabel 7. Identifikasi Ancaman

\begin{tabular}{llll}
\hline \multicolumn{1}{c}{ Nama Aset } & Nilai & \multicolumn{1}{c}{ Nilai } & Status \\
\hline Data Karyawan & Aset & Ancaman & \\
Data PSB & 9 & 0,46 & Medium \\
Data Sekolah & 12 & 0,46 & Medium \\
Data Keasramaan & 11 & 0,46 & Medium \\
Data Tahfidz & 11 & 0,46 & Medium \\
Data Laboratorium Komputer & 12 & 0,46 & Medium \\
Aplikasi MySchool & 12 & 0,55 & Medium \\
Aplikasi PSB & 10 & 0,55 & Medium \\
Aplikasi Ujian Quran & 8 & 0,55 & Medium \\
Aplikasi Asrama & 11 & 0,55 & Medium \\
Mikrotik & 12 & 0,6 & Medium \\
Server & 12 & 0,5 & Medium \\
Komputer Laboratorium & 8 & 0,42 & Medium \\
Komputer Backup Server & 8 & 0,47 & Medium \\
Komputer Asrama & 10 & 0,42 & Medium \\
Komputer Tahfidz & 8 & 0,42 & Medium \\
Komputer Admin & 12 & 0,42 & Medium \\
CCTV Labkom & 12 & 0,6 & Medium \\
AC & 9 & 0,56 & Medium \\
Fire Extinguisher & 8 & 0,6 & Medium \\
Dengan kriteria penilaian sebagai berikut: & & Medium \\
Low = Nilai Rerata $0,1-0,3$ & & & \\
Medium = Nilai Rerata 0,4-0,6 & & & \\
High = Nilai Rerata 0,7-1,0 & & & \\
\hline \hline
\end{tabular}

http://journal.uinjkt.ac.id/index.php/aism
B. Do
1) Analisa dan Evaluasi Resiko
a) Analisa Dampak Bisnis

Tabel 8. Nilai BIA

\begin{tabular}{|c|c|c|c|}
\hline Fasilitas Informasi & Impact & $\begin{array}{l}\text { Nilai } \\
\text { BIA }\end{array}$ & Status \\
\hline Data Karyawan & Data Hilang & 85 & $\begin{array}{l}\text { Very high } \\
\text { critical }\end{array}$ \\
\hline Data Penerimaan Siswa Baru & Data Hilang & 25 & $\begin{array}{l}\text { Minor } \\
\text { critical }\end{array}$ \\
\hline Data Sekolah & Data Hilang & 90 & $\begin{array}{l}\text { Very high } \\
\text { critical }\end{array}$ \\
\hline Data Keasramaan & Data Hilang & 90 & $\begin{array}{l}\text { Very high } \\
\text { critical }\end{array}$ \\
\hline Data Tahfidz & Data Hilang & 90 & $\begin{array}{l}\text { Very high } \\
\text { critical }\end{array}$ \\
\hline Data Laboratorium Komputer & Data Hilang & 25 & $\begin{array}{l}\text { Minor } \\
\text { critical }\end{array}$ \\
\hline Aplikasi MySchool & $\begin{array}{l}\text { Aplikasi } \\
\text { tidak dapat } \\
\text { digunakan }\end{array}$ & 100 & $\begin{array}{l}\text { Very high } \\
\text { critical }\end{array}$ \\
\hline Aplikasi PSB & $\begin{array}{c}\text { Aplikasi } \\
\text { tidak dapat } \\
\text { digunakan }\end{array}$ & 40 & $\begin{array}{l}\text { Minor } \\
\text { critical }\end{array}$ \\
\hline Aplikasi Ujian Quran & $\begin{array}{c}\text { Aplikasi } \\
\text { tidak dapat } \\
\text { digunakan }\end{array}$ & 70 & High critical \\
\hline Aplikasi Asrama & $\begin{array}{c}\text { Aplikasi } \\
\text { tidak dapat } \\
\text { digunakan }\end{array}$ & 100 & $\begin{array}{l}\text { Very high } \\
\text { critical }\end{array}$ \\
\hline Mikrotik & $\begin{array}{l}\text { Jaringan } \\
\text { Terputus }\end{array}$ & 100 & $\begin{array}{l}\text { Very high } \\
\text { critical }\end{array}$ \\
\hline Server & $\begin{array}{l}\text { Operasi } \\
\text { terhenti }\end{array}$ & 100 & $\begin{array}{l}\text { Very high } \\
\text { critical }\end{array}$ \\
\hline Komputer Laboratorium & $\begin{array}{l}\text { Operasi } \\
\text { terhenti }\end{array}$ & 50 & $\begin{array}{l}\text { Mayor } \\
\text { critical }\end{array}$ \\
\hline Komputer Backup Server & $\begin{array}{l}\text { Operasi } \\
\text { terhenti }\end{array}$ & 80 & High critical \\
\hline Komputer Asrama & $\begin{array}{l}\text { Operasi } \\
\text { terhenti }\end{array}$ & 100 & $\begin{array}{l}\text { Very high } \\
\text { critical }\end{array}$ \\
\hline Komputer Tahfidz & $\begin{array}{l}\text { Operasi } \\
\text { terhenti }\end{array}$ & 80 & $\begin{array}{l}\text { Very high } \\
\text { critical }\end{array}$ \\
\hline Komputer Admin & $\begin{array}{l}\text { Operasi } \\
\text { terhenti }\end{array}$ & 95 & $\begin{array}{l}\text { Very high } \\
\text { critical }\end{array}$ \\
\hline CCTV Labkom & $\begin{array}{l}\text { Operasi } \\
\text { terhenti }\end{array}$ & 90 & $\begin{array}{l}\text { Very high } \\
\text { critical }\end{array}$ \\
\hline $\begin{array}{l}\text { Pendingin Ruangan (AC) } \\
\text { Labkom }\end{array}$ & $\begin{array}{l}\text { Operasi } \\
\text { terhenti }\end{array}$ & 95 & $\begin{array}{l}\text { Very high } \\
\text { critical }\end{array}$ \\
\hline Fire Extinguisher & $\begin{array}{c}\text { Terjadi } \\
\text { Kebakaran }\end{array}$ & 90 & $\begin{array}{l}\text { Very high } \\
\text { critical }\end{array}$ \\
\hline
\end{tabular}

\section{2) Mengestimasi Level Resiko}

Setelah ditemukannya nilai aset, nilai ancaman (NT) dan nilai BIA, maka kita dapat menimbang level resiko masing-masing aset informasi di Kafila International Islamic School. Namun sebelum perhitungan dimulai, terlebih dahulu 
penulis membuat matriks level resiko yang variabelnya diambil dari variabel nilai aset, nilai ancaman dan nilai BIA

\section{3) Menentukan Penerimaan Resiko}

Penulis menilai resiko berdasarkan hitungan menggunakan metode matematis sebagai berikut;

Tabel 9. Pengukuran Tingkat resiko

\begin{tabular}{|c|c|c|c|c|c|}
\hline Nama Aset & $\begin{array}{l}\text { Nilai } \\
\text { Aset }\end{array}$ & BIA & $\begin{array}{c}\text { Nilai } \\
\text { Ancaman }\end{array}$ & $\begin{array}{l}\text { Risk } \\
\text { Value }\end{array}$ & Status \\
\hline Data Karyawan & 9 & 85 & 0,46 & 496,8 & $\begin{array}{l}\text { High } \\
\text { Risk }\end{array}$ \\
\hline $\begin{array}{l}\text { Data Penerimaan } \\
\text { Siswa Baru }\end{array}$ & 9 & 25 & 0,46 & 455,4 & $\begin{array}{l}\text { High } \\
\text { Risk }\end{array}$ \\
\hline Data Sekolah & 12 & 90 & 0,46 & 455,4 & $\begin{array}{l}\text { High } \\
\text { Risk }\end{array}$ \\
\hline $\begin{array}{l}\text { Data } \\
\text { Keasramaan }\end{array}$ & 11 & 90 & 0,46 & 138 & $\begin{array}{l}\text { High } \\
\text { Risk }\end{array}$ \\
\hline Data Tahfidz & 11 & 90 & 0,46 & 660 & $\begin{array}{l}\text { High } \\
\text { Risk }\end{array}$ \\
\hline $\begin{array}{l}\text { Data } \\
\text { Laboratorium } \\
\text { Komputer }\end{array}$ & 12 & 25 & 0,46 & 220 & $\begin{array}{l}\text { High } \\
\text { Risk }\end{array}$ \\
\hline $\begin{array}{l}\text { Aplikasi } \\
\text { MySchool }\end{array}$ & 12 & 100 & 0,55 & 308 & $\begin{array}{l}\text { High } \\
\text { Risk }\end{array}$ \\
\hline Aplikasi PSB & 10 & 40 & 0,55 & 605 & $\begin{array}{l}\text { High } \\
\text { Risk }\end{array}$ \\
\hline $\begin{array}{l}\text { Aplikasi Ujian } \\
\text { Quran }\end{array}$ & 8 & 70 & 0,55 & 720 & $\begin{array}{l}\text { High } \\
\text { Risk }\end{array}$ \\
\hline Aplikasi Asrama & 11 & 100 & 0,55 & 600 & $\begin{array}{l}\text { High } \\
\text { Risk }\end{array}$ \\
\hline Mikrotik & 12 & 100 & 0,6 & 168 & $\begin{array}{l}\text { High } \\
\text { Risk }\end{array}$ \\
\hline Server & 12 & 100 & 0,5 & 300,8 & $\begin{array}{l}\text { High } \\
\text { Risk }\end{array}$ \\
\hline $\begin{array}{l}\text { Komputer } \\
\text { Laboratorium }\end{array}$ & 8 & 50 & 0,42 & 420 & $\begin{array}{l}\text { High } \\
\text { Risk }\end{array}$ \\
\hline $\begin{array}{l}\text { Komputer } \\
\text { Backup Server }\end{array}$ & 8 & 80 & 0,47 & 268,8 & $\begin{array}{l}\text { High } \\
\text { Risk }\end{array}$ \\
\hline $\begin{array}{l}\text { Komputer } \\
\text { Asrama }\end{array}$ & 10 & 100 & 0,42 & 478,8 & $\begin{array}{l}\text { High } \\
\text { Risk }\end{array}$ \\
\hline $\begin{array}{l}\text { Komputer } \\
\text { Tahfidz }\end{array}$ & 8 & 80 & 0,42 & 648 & $\begin{array}{l}\text { High } \\
\text { Risk }\end{array}$ \\
\hline $\begin{array}{l}\text { Komputer } \\
\text { Admin }\end{array}$ & 12 & 95 & 0,42 & 478,8 & $\begin{array}{l}\text { High } \\
\text { Risk }\end{array}$ \\
\hline CCTV Labkom & 12 & 90 & 0,6 & 432 & $\begin{array}{l}\text { High } \\
\text { Risk }\end{array}$ \\
\hline $\mathrm{AC}$ & 9 & 95 & 0,56 & 496,8 & $\begin{array}{l}\text { High } \\
\text { Risk }\end{array}$ \\
\hline $\begin{array}{l}\text { Fire } \\
\text { Extinguisher }\end{array}$ & 8 & 90 & 0,6 & 455,4 & $\begin{array}{l}\text { High } \\
\text { Risk }\end{array}$ \\
\hline
\end{tabular}

\section{Check}

1) Identifikasi dan Evaluasi Pilihan Penanganan Resiko

Setelah penulis melakukan analisa dan evaluasi resiko apasaja yang kerap mungkin terjadi pada fasilitas IT KIIS, berikut penanganan resiko yang dapat direncanakan:

a) Apabila hasilnya "diterima", maka perlu menerapkan kontrol keamanan yang sesuai. b) Apabila hasilnya direduksi, hampir sama dengan poin 1, dengan beberapa penambahan pasal untuk keamanan.

c) Resiko yang dapat ditransfer kepada pihak ketiga, akan diatur juga dalam pasal poin 1 .

\section{2) Pemilihan Obyek Kontrol dan Kontrol untuk Pengelolaan Resiko}

Dengan adanya beberapa kerentanan dalam data, aplikasi dan fasilitas fisik IT, maka penulis menemukan kontrol obyek dalam ISO 27002 yang berhubungan sesuai dengan dokumentasi ISO 27002:2013 (BSI, 2013), yaitu: Information security policies (klausul 5), Organizational of information security (klausul 6), Human resource security (klausul 7), Asset management (klausul 8), Access control (klausul 9), Physical and environment security (klausul 11), Operation security (klausul 12), dan System acquisition development and maintenance (klausul 14).

\section{3) Wawancara}

Tabel dibawah menunjukkan bagian yang akan diwawancara berdasarkan klausul yang telah ditentukan:

Tabel 10. Narasumber

\begin{tabular}{cll}
\hline \hline Klausul & \multicolumn{1}{c}{ Deskripsi } & \multicolumn{1}{c}{ Bagian } \\
\hline 5 & Kebijakan keamanan informasi & HRD \\
6 & Keamanan Informasi Organisasi & Kepala \\
7 & Keamanan Sumber Daya & Sarana dan \\
& Manajemen Aset & Prasarana \\
8 & & Kepala \\
& Kontrol Akses & Labkom \\
& & Kepala \\
9 & Keamanan fisik dan lingkungan & Sarana dan \\
& & Prasarana \\
& & Kepala \\
11 & Keamanan operasi & Kepala \\
& & Sarana dan \\
12 & Akusisi sistem informasi, & Prasarana \\
\hline
\end{tabular}

D. Act, Usulan Perbaikan Sistem Informasi

Berikut adalah perolehan dari seluruh Klausul:

Tabel 11. Nilai Kematangan Seluruh Klausul

\begin{tabular}{ll}
\hline \hline \multicolumn{1}{c}{ Klausul } & Maturity Level \\
\hline 5. Kebijakan Keamanan Informasi & 4 \\
6. Keamanan Informasi Organisasi & 4 \\
7. Keamanan Sumber Daya (pekerjaan) & 4 \\
8. Manajemen Aset & 4,35 \\
9. Kontrol Akses & 3,75 \\
11. Keamanan fisik dan lingkungan & 3,03 \\
12. Keamanan operasi & 2,9 \\
14. Akusisi sistem informasi, pembangunan dan & 3,5 \\
pemeliharaan & \multicolumn{2}{l}{} \\
\hline \hline
\end{tabular}




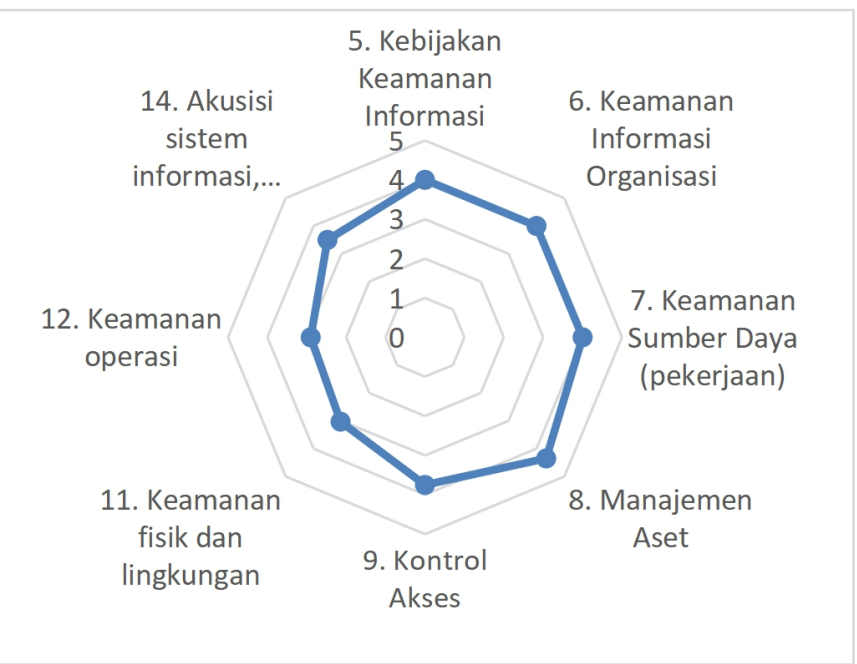

Gambar 2. Hasil Tingkat Kematangan dari Seluruh Klausul

Berikut adalah representasi dari hasil maturity level seluruh klausul.

1) Pada klausul 5, KIIS memperoleh nilai maturity level sebesar 4 dan berada pada tingkat managed.

2) Pada klausul 6, KIIS memperoleh nilai maturity level sebesar 4 dan berada pada tingkat managed.

3) Pada klausul 7, KIIS memperoleh nilai maturity level sebesar 4 dan berada pada tingkat managed.

4) Pada klausul 8, KIIS memperoleh nilai maturity level sebesar 4,35 dan berada pada tingkat managed.

5) Pada klausul 9, KIIS memperoleh nilai maturity level sebesar 3,75 dan berada pada tingkat managed.

6) Pada klausul 11, KIIS memperoleh nilai maturity level sebesar 3,03 dan berada pada tingkat defined.

Berikut adalah beberapa rekomendasi yang dapat disimpulkan oleh penulis sebagai best practice dalam perbaikan keamanan informasi pada Kafila International Islamic School.

\section{1) Prosedur dan Dokumentasi}

Berikut adalah rekomendasi penulis mengenai klausul yang bermasalah sesuai pada best practice ISO 27002:

a) Klausul 6.2 Pada Perangkat Seluler dan Teleworking, Pedoman dan pengaturan mengenai telekomukasi harus mencakup:

(1) Penyediaan peralatan khusus kegiatan teleworking oleh kantor, dimana penggunaan peralatan kantor hanya digunakan untuk keperluan kantor.

(2) Penyediaan peralatan komunikasi yang sesuai, termasuk metode untuk mengamankan akses jarak jauh.

(3) Keamanan fisik perangkat keras.
(4) Penyediaan dukungan dan pemeliharaan perangkat keras dan perangkat lunak (asuransi dan bantuan service)

(5) Prosedur untuk backup data.

(6) Audit dan pemantauan keamanan;

(7) Pencabutan wewenang dan hak akses, dan pengembalian peralatan saat kegiatan teleworking dihentikan/sudah waktunya diambil kembali oleh sekolah.

b) Klausul 9 pada Kontrol Akses, kebijakan mengenai hal tersebut harus mempertimbangkan:

(Persyaratan keamanan aplikasi sekolah yang dipakai oleh guru (MySchool, Kafiqu dan EMIS).

(1) Konsistensi antara hak akses dan kebijakan akses pada informasi sistem dan jaringan.

(2) Pengelolaan hak akses yang tepat sesuai bidang dalam sekolah, pada semua jenis koneksi yang disediakan KIIS, dalam hal ini adalah akses Mikrotik.

(3) Pemisahan peran kontrol akses, misalkan permintaan akses, otorisasi akses, administrasi akses kepada kepala labkom selaku administrator.

(4) Persyaratan untuk otorisasi harus resmi dari administrator dan didokumentasikan.

(5) Peninjauan berkala akan hak-hak akses semua guru agar akses informasi sesuai dengan bidangnya.

(6) Pengarsipan catatan semua peristiwa penting terkait dalam penggunaan hak akses (semua log tersimpan).

(7) Tidak di-share-nya informasi hak akses administrator kecuali hanya pada bidang yang berwenang.

Proses untuk mengelola ID pengguna harus mencakup:

(a) Menggunakan ID pengguna unik untuk memungkinkan pengguna untuk ditautkan dan bertanggung jawab atas tindakan mereka dan penggunaan ID bersama hanya diizinkan jika diperlukan untuk keperluan bisnis atau operasional dan harus disetujui dan didokumentasikan;

(b) Segera menonaktifkan atau menghapus ID pengguna dari pengguna yang telah meninggalkan organisasi (seperti pada klausul 9.2.6)

(c) Secara berkala mengidentifikasi dan menghapus atau menonaktifkan ID pengguna yang berlebihan (id ganda);

(d) Memastikan bahwa ID pengguna yang berlebihan tidak diberikan kepada pengguna lain. 
c) Klausul 12.3 pada Prosedur Backup, hal-hal berikut harus dipertimbangkan merencanakan prosedur pencadangan:

(1) Data/informasi harus utuh, tidak parsial;

(2) Tingkat dan frekuensi cadangan harus dijadwalkan teratur;

(3) Cadangan harus disimpan di lokasi khusus, tidak pada lokasi-lokasi umum. Dalam hal ini, KIIS sudah melakukan dengan penempatan server yang jauh dari tempat umum.

(4) Media cadangan (hdd server) harus diuji (chkdisk) secara berkala untuk memastikan bahwa perangkay penyimpanan tersebut dapat diandalkan untuk penggunaan darurat. Ini harus dilengkapi dengan uji restorasi data. Melakukan backup tanpa overwrite data yang lama, dalam artian jika ada kegagalan dalam pencadangan, cadangan data yang sebelumnya masih tersedia;

(5) Pada data yang sangat penting, cadangan harus dilindungi dengan cara enkripsi.

d) Klausul 12.6 pada Pengaturan Operasional Perangkat Lunak, panduan berikut harus diikuti dan didokumentasikan untuk menerapkan prosedur yang baik:

(1) Organisasi harus menetapkan peran dan tanggung jawab yang terkait dengan kerentanan (vulnerability), termasuk ceklis pemantauan kerentanan, penilaian risiko kerentanan, perbaikan, log dokumentasi aset, dan koordinasi tanggung jawab pada bidangnya masing-masing;

(2) Log ceklis evaluasi harus disimpan untuk semua prosedur yang dilakukan;

(3) Proses manajemen kerentanan teknis harus secara teratur dipantau dan dievaluasi untuk memastikan efektivitas dan efisiensinya;

(4) Sistem yang berisiko tinggi harus ditangani terlebih dahulu, dalam hal ini fungsi aplikasi MySchool harus mendapat perhatia lebih mengingat ini adalah aplikasi pusat kegiatan KBM sekolah;

(5) Proses manajemen kerentanan teknis ini harus diselaraskan dengan kegiatan manajemen insiden, untuk mengformulasikan tentang kerentanan data sebelum terjadi insiden;

(6) Menetapkan prosedur antisipasi jika timbul kerentanan risiko dan mengawasinya sehingga dapat membantu menentukan tindakan korektif yang cepat dan tepat.

http://journal.uinjkt.ac.id/index.php/aism
Aplikasi Pencadangan, aplikasi yang dikembangkan KIIS sudah cukup aman dan multifungsi, sudah sangat terintegrasi dengan baik, namun belum menyentuh mengenai backup data. Mengingat data yang banyak memerlukan penyimpanan yang banyak, penulis tetap menganjurkan bahwa aplikasi backup yang dipakai adalah aplikasi linux server dan mempunyai fitur backup secara berkala.

\section{KESIMPULAN}

Berdasarkan penguraian pada bab sebelumnya, penulis menyimpulkan penelitian pada Keamanan Sistem Informasi di Kafila International Islamic School ini adalah: penelitian evaluasi keamanan sistem informasi Kafila International Islamic School dengan Standar ISO 27002:2013 menggunakan klausul 5 mengenai Kebijakan Keamanan Informasi, klausul 6 mengenai Keamanan Informasi Organisasi, klausul 7 mengenai Keamanan Sumber Daya, klausul 8 mengenai Manajemen Aset, klausul 9 mengenai Kontrol Akses, klausul 11 mengenai Keamanan Fisik dan Lingkungan, klausul 12 mengenai Keamanan Informasi dan klausul 14 mengenai Akuisisi Sistem Informasi, Pembangunan dan Pemeliharaan. Pada pengukuran tingkat resiko, semua aset yang diukur mempunyai high risk, artinya hampir semua aset sangat penting dan berpengaruh pada kelangsungan kegiatan organisasi. Namun berbeda dengan setelah dilakukan penelitian, KIIS sudah mempunyai dokumentasi $(\log )$ yang cukup baik. Hanya ada 3 klausul yang mempunyai nilai rendah yaitu keamanan fisik/lingkungan, keamanan operasi dan Akusisi sistem informasi, pembangunan dan pemeliharaan. Adapun pasal yang paling rendah, adalah:

1) Pada klausul keamanan fisik/lingkungan, sangat kurang pada kebijakan pembatasan masuk ruangan, masih terjadi keluar/masuk ruangan penting (seperti ruang labkom dan ruang kontrol) tanpa izin dan belum adanya sanksi pelanggaran jika ada SDM yang melakukan hal tersebut.

2) Pada klausul keamanan operasi, sangat lemah terhadap proteksi data, termasuk di dalamnya belum ada prosedur backup data server, prosedur penggunaan aplikasi hingga belum adanya $\log$ yang rapih dan pengawasan akses secara berkala terhadap aplikasi-aplikasi yang digunakan KIIS.

3) Pada klausul pemeliharaan sistem aplikasi, sangat kurang pada proses testing, belum ada pembuatan panduan penggunaan aplikasi, belum adanya tester aplikasi hingga pada peninjauan kembali aplikasi secara berkala. Perbaikan terjadi jika/hanya ditemukan bug/error saja.

Rata-rata penilaian dari semua klausul yang diteliti adalah managed, artinya Kafila International Islamic School sudah hampir menjalankan dokumentasi keamanan sistem informasi (sebagian dokumentasi terbantu oleh implementasi dokumentasi ISO 9001:2008). Dengan temuan pada sistem manajamen IT KIIS, KIIS dapat membuat SOP-SOP baru yang berhubungan dengan Aset IT dan Aplikasi KIIS, seperti SOP pada pembuatan dan pemakaian aplikasi, pencatatan dan pemeliharaan aset yang lengkap dan teratur, pelatihan-pelatihan keamanan dan aplikasi keamanan hingga 
pada sanksi terhadap pelanggaran penggunaan aset IT dan aplikasi untuk tujuan yang tidak semestinya.

\section{REFERENSI}

[1] I. Santosa and D. Kuswanto, "Analisa Manajemen Resiko Keamanan Informasi pada Kantor Pelayanan Pajak Pratama XYZ," vol. 9, no. 2, pp. 108-115, 2016.

[2] H.K. Fitriyadi, "Integrasi teknologi informasi komunikasi dalam pendidikan: potensi manfaat, masyarakat berbasis pengetahuan, pendidikan nilai, strategi implementasi dan pengembangan profesional," vol. 21 , no. $3,2013$.

[3] J. Ward and J. Peppard, Strategic planning for information systems. John Wiley \& Sons, Inc, 2002.

[4] R. Yustiani and R. J.Yunanto, "Peran Marketplace Sebagai Alternatif Bisnis di Era Teknologi Informasi," vol. 6, no. 2, 2017.

[5] M. Pribadi, "Penerapan tata kelola teknologi informasi dengan menggunakan COBIT Framework 4.1 (studi kasus pada RSUD Bari Palembang)," vol. 4, no. 2, pp. 115-124, 2015.

[6] M. Chander, S. K. Jain, and R. Shankar, "Modeling of information security management parameters in Indian organizations using ISM and MICMAC approach," 2013.

[7] F. Mauladani, "Perancangan Sistem Manajemen Keamanan Informasi (Smki) Berdasarkan Sni Iso/Iec 27001: 2013 Dan Sni Iso/Iec 27005:
2013 (Studi Kasus Dptsi-Its)," Institut Teknologi Sepuluh Nopember, 2017.

[8] F. Mahardika, "Manajemen Risiko Keamanan Informasi Menggunakan Framework NIST SP 800-30 Revisi 1 (Studi Kasus: STMIK Sumedang)," vol. 2, no. 2, pp. 1-8, 2017.

[9] R. Amalyah, D. Hamid, and L. B. Hakim, "Peran stakeholder pariwisata dalam pengembangan Pulau Samalona sebagai destinasi wisata bahari," vol. 37, no. 1, pp. 158-163, 2016.

[10] M. S. Mustaqbal, R. F. Firdaus, and H. Rahmadi, "Pengujian aplikasi menggunakan black box testing boundary value analysis (studi kasus: Aplikasi prediksi kelulusan smnptn)," vol. 1, no. 3, 2015.

[11] K. H. Dewantara, "Identifikasi, Penilaian, dan Mitigasi Risiko Keamanan Informasi Berdasarkan Standar ISO 27001: 2005 dan ISO 27002: 2013 Menggunakan Metode Fmea (Studi Kasus: ISNET)," Institut Teknologi Sepuluh Nopember, 2016.

[12] S. Hariyanto, "Sistem Informasi Manajemen," vol. 9, no. 1, pp. 80-85, 2016.

[13] D. D. Laksana, S. Ismail, and N. A. S.Hendrarini, "Implementasi Honeypot Dengan Modern Honey Network," vol. 3, no. 3, 2017.

[14] E. D. Meutia, "Internet of things-Keamanan dan Privasi," in Seminar Nasional dan Expo Teknik Elektro, 2015, vol. 1, no. 1, pp. 85-89.

[15] B. Purnomo, "Metodedan Teknik Pengumpulan Data dalam Penelitian Tindakan Kelas (Classroomaction Research)," vol. 8, no. 1, p. 210251, 2011. 